\title{
BENDAÑA, ALEJANDRO. BUENAS AL PLEITO: MUJERES EN LA REBELIÓN DE SANDINO. ANAMA, S.L. (MANAGUA), S.F. (2019)
}

Sergio Villena Fiengo

Recibido: 18/06/19 - Aceptado: 22/07/19

Presento una reseña crítica del libro Buenas al pleito: Mujeres en la rebelión de Sandino, de Alejandro Bendaña. En la primera parte, haré referencia al autor y a los aspectos formales del libro; en la segunda, propongo -desde una lectura "sociológica"- una reconstrucción de las tesis y argumentos principales del libro. A pie de página, mencionaré las referencias teóricas a las que acudo, así como a los pasajes del libro de Bendaña que ilustran esa reconstrucción. Este ejercicio se benefició de los intercambios realizados con el autor y comentaristas (Lucía Brenes, Yadira Calvo y Mijail Mondol) y el público, durante dos presentaciones del libro realizadas en abril de 2019 en el Instituto de Investigaciones Sociales de la Universidad de Costa Rica y la Sede de Occidente de dicha universidad.

\section{El autor y los aspectos formales del libro}

El autor es Doctor en Historia por la Universidad de Harvard y especialista en la figura de Sandino, sobre quien ha publicado La mística de Sandino (1994), Sandino: Mística, Libertad y Socialismo (2007) y Sandino, Patria y Libertad (2016). Esta última ha sido considerada por The American Historical Review (2018) la biografía más atractiva y definitiva de Augusto C. Sandino.

El libro está estructurado en 17 capítulos, más la introducción y las conclusiones, lo cual suma 286 páginas. Incluye también, sin numerar, una nota bibliográfica, la bibliografía y, algo que siempre se agradece, un índice onomástico. La bibliografía contiene solo referencias principales; las secundarias se realizan a pie de página. Se introducen también fotografías, pero no existe un índice de ilustraciones, las cuales tampoco están numeradas.

El diagramado y el tamaño de letra facilitan la lectura, la cual también se beneficia de una redacción amena y fluida. El aparato crítico y las abundantes fuentes son referidos con detalle a pie de página. Para una eventual segunda edición, sería recomendable una revisión exhaustiva de los errores "de dedo" contenidos en esta primera edición, así como algunas imprecisiones en el índice onomástico. 
Si bien el libro tiene un Número Estándar Internacional de Libros (ISBN, por sus siglas en inglés), no presenta la ficha respectiva, lo cual impide conocer el año de publicación, entre otros detalles importantes. De acuerdo con una comunicación personal del autor, esa carencia se debe a que la oficina de la Biblioteca Nacional de Nicaragua negó el registro catalográfico de esta obra, lo que en sí mismo constituye un indicador de cómo el clima político actual en Nicaragua está afectando la labor editorial.

\section{El contenido}

El objetivo general del libro es reconstruir el lugar y el papel de las mujeres en la rebelión sandinista. A partir de la propuesta teórica de Butler, podríamos decir que Bendaña busca conocer las formas de aparición de las mujeres en el espacio bélico nicaragüense, las normas culturales que regulan esa aparición y las transformaciones y subversiones a ese sistema normativo, en particular aquellas introducidas por el propio Sandino y las mujeres que se relacionan directamente con su rebelión.

El texto arranca con una referencia a Sandino y a su apreciación sobre el papel de las mujeres en su movimiento: el de Niquinohomo reconoce que habían "muchísimas mujeres" y expresa su intención de encargar una publicación especial para rendirles "el homenaje que merecen, pues sus nombres y sus hechos constituyen una verdadera gloria para Nicaragua y deben incorporarse a la Historia Patria" (Bendaña 11). Ese deseo del "general de hombres libres" no se habría cumplido y habría sido ignorado por la historiografía nicaragüense, incluida la sandinista, la cual concentró su atención en la exaltación de la figura de Sandino.

Bendaña se hace cargo de esa deuda con las mujeres que participaron en la rebelión, invisibles en la "Historia Patria" por poco menos de un siglo. El libro muestra su simpatía con esas mujeres y sus herederas, como queda evidenciado en la dedicatoria a Lea Guido, una destacada intelectual y luchadora histórica del Frente Sandinista de Liberación Nacional (FSLN), así como a las "continuadoras de 1979 y 2018", es decir, a las hijas y nietas no de Sandino, sino de las mujeres que participaron en la rebelión del héroe de las Segovias.

El autor señala, con Lucía Rayas Velasco, que el espacio bélico se ha concebido y construido como esencialmente masculino e identifica dos líneas de indagación, entre las cuales oscila su investigación. Por un lado, las diversas manifestaciones e impacto de la violencia: mujeres como bajas directas de la guerra, su desplazamiento, la violencia sexual, así como la pérdida de familiares y de estructuras familiares y económicas. Por otro lado, la respuesta de las mujeres a la guerra y su integración participativa en estas (26-27). Es decir, lo que la guerra les hace a las mujeres y lo que las mujeres hacen en la guerra.

Ahora bien, ¿cuál fue la situación durante la rebelión de Sandino? Contra lo habitual, Bendaña no restringe su indagación a "las mujeres que amaron a Sandino", 
a las cuales ya había dedicado atención en Sandino, Patria y Libertad (1994), pues incluye a las mujeres que -de diversas maneras- participaron en las luchas sandinistas, así como a las mujeres que no acudieron al llamado de Sandino. ${ }^{1}$ Más aún, refiere incluso a aquellas que fueron parte del bando opositor, en cuenta las que abiertamente simpatizaron con los mariners (dedica el capítulo XII a las denominadas flappers nicaragüenses). ${ }^{2}$

El libro identifica y caracteriza a las mujeres que participaron en el conflicto, en uno u otro bando, asimismo, relata cómo Sandino, los sandinistas y sus oponentes concebían el papel de la mujer en la sociedad y en el conflicto. Así, reconstruye las relaciones entre géneros (incluyendo también referencia a las relaciones entre clases y etnias), sobre todo en el marco de la vida cotidiana que tenía lugar en los campamentos guerrilleros, así como en la relación entre estos y su entorno social.

En cuanto a las fuentes, el autor -como historiador con oficio- revisa exhaustivamente los materiales disponibles en el sitio web sandinorebellion.com, el Instituto de Historia de Nicaragua y Centroamérica (IHNCA) y otros repositorios, en Nicaragua y en EE. UU., así como los libros y audiovisuales dedicados a la vida y obra de Sandino. ${ }^{3}$ La mayor parte de esos documentos fueron escritos/fotografiados por hombres de uno y otro bando, así como por algunos observadores "neutrales": informes de inteligencia, noticias o artículos de opinión, correspondencia personal y testimonios. Es decir, las referencias a las mujeres en esos documentos están mediadas por la mirada y la escritura masculina y tienen un carácter -o al menos un tono- anecdótico.

Una interesante excepción al sesgo masculino es la expresión que da lugar al título del libro, "Buenas al pleito”, calificativo que utiliza una de las mujeres que estuvo involucrada en la rebelión de Sandino, Luisa Cano Aráuz, al referirse "a dos muchachas que andaban con los sandinistas: Rosa y María. Aguerridas como las de ahora, buenas al pleito". La frase, que data de los años ochenta y es reproducida en el epígrafe inicial, es atractiva y convoca a la lectura, pero corre el riesgo de establecer a prori un significado "maestro" como rasgo central del papel y la agencia de las mujeres en la rebelión de Sandino, lo cual -como muestra el mismo autor- no es generalizable.

La composición del libro recuerda el "método anecdótico" de la socióloga Nathalie Heinich. Es un mosaico de relatos cortos, anécdotas e instantáneas, en el cual se incluyen extensas citas literales extraídas de los testimonios y relatos originales (traducidas en algunos casos del inglés por el propio Bendaña), centrados en algunos episodios específicos (en general, el apartado se titula tomando una frase significativa del relato) o en personajes puntuales (en cuyo caso el título es el nombre del personaje en cuestión).

En cuanto a los hallazgos, desde una lectura sociológica, se pueden identificar y abstraer los siguientes tópicos centrales que se despliegan transversalmente y sobre los cuales (de manera implícita, más allá de los relatos anecdóticos) se arma argumentativamente la trama del libro: 
- A inicios del siglo XX, en Nicaragua existe una gran violencia política, social y de género con gran impacto en lo cotidiano. Especialmente crueles y desalmadas son las acciones de los grupos bandoleros que actúan en las Segovias, apoyados por los "gamonales conservadores chamorristas". La violencia conservadora y bandolera contra las mujeres, los campesinos y los trabajadores de las minas, remite a las injusticias y a lo que, retomando el título de un famoso libro de Barrington Moore, podría denominarse "las bases sociales de la rebelión".

- La ocupación militar norteamericana (1912-1933) agudiza esa violencia, introduciendo elementos adicionales de agresión cultural, sexual y racial, sumando una nueva injusticia: la humillación imperial hacia la nación nicaragüense. La violencia sexual la sufrieron no solamente las mujeres que simpatizaban con el sandinismo, sino las nicaragüenses en general, incluidas algunas de clase alta. Los mariners parecen haber asumido que poseían una "superioridad racial" que les daba derecho a agredir a las "indias", considerando incluso que estas deberían sentirse honradas por ello! Las mujeres resintieron también la agresión religiosa/cultural, la cual incluyó la profanación de lugares y objetos sagrados: cementerios, iglesias y objetos litúrgicos (católicos), fueron atacadas por los mariners (probablemente protestantes, en su mayoría), quienes mostraron una insensibilidad absoluta por la diferencia cultural. El recuento de los daños incluye también otras formas de crueldad contra la población civil; particular indignación habría generado el asesinato de niños (caso Macho Alí), así como dejar morir de hambre a la población civil "reconcentrada".

- Todo ello habría contribuido a fortalecer la causa rebelde: "El odio entonces fue el primero y más grande aliado de Sandino" (154). Sandino -quien había pasado unos años trabajando en México poco tiempo después del estallido revolucionario de 1910-1917- entra en escena con una propuesta distinta ("moralmente superior") y canaliza la indignación de los sectores agraviados hacia una lucha nacional y social. Más allá de la desobediencia, el motín o el "arte de la resistencia" callada (Scott), Sandino canaliza la indignación y "la economía moral de la multitud" (Thompson) hacia la lucha armada organizada, la cual cristaliza institucionalmente con la formación del Ejército Defensor de la Soberanía Nacional de Nicaragua (EDSNN).

- Si bien sus adversarios -como el propio Somoza en su libro El verdadero Sandino o el calvario de las Segovias (1936) - trataron de mostrarlo como un bandolero más, Sandino establece ciertos principios y un código de comportamiento entre su tropa (reglamento del Estado Mayor del EDSNN), con los cuales busca marcar la diferencia, tanto militar como ética, con el bandolerismo. ${ }^{5}$ Existen diversos estudios -que no se mencionan en el libro que reseñamos- que han mostrado también el cuidado que ponía Sandino en su apariencia y comportamiento, estableciendo su propia iconografía y carisma individual.

- La visión, el ideario y la conducta de Sandino -cercanos a los liberales al inicio de sus luchas- se reflejan en el reglamento, el cual condena y penaliza tres 
vicios: el alcoholismo, el saqueo y la violación. ${ }^{6}$ Él, quien no siempre aplicaba con rigor su reglamento, aunque sí llegó a fusilar a alguno de sus cercanos colaboradores acusado de violación, no es un feminista, pero tampoco un puritano, ya que permite, incluso estimula, a sus hombres a "pastorear" a las mujeres, cuando no -como ocurre en relación con las miskitas-- a engendrar con ellas, promoviendo el mestizaje. Sin embargo, muestra una sensibilidad mayor que los conservadores y los mariners hacia las demandas específicas de las mujeres, muchas de las cuales se pliegan a su lucha -al menos en un principio- en busca de seguridad y protección: "pelean por oído" (32). ${ }^{7}$

- Ese código y el propio comportamiento "empático" de Sandino dejan entrever lo que Bendaña denomina una "ética del cuido". Si bien se mantiene la división del trabajo por género de la época, restringiendo el papel "activo" bélico para los hombres, se establece también una protección especial hacia las mujeres. ${ }^{8}$ ${ }^{9}$ Eso le permite ganar adherentes para su causa, contando muchas mujeres, la mayor parte de las cuales participó en la rebelión como apoyo logístico y permaneció en el anonimato. El apoyo de la población civil fue fundamental para el éxito de la resistencia sandinista en la zona norte de Nicaragua, fronteriza con Honduras. ${ }^{10}$

- La vida cotidiana en el campamento militar está marcada por la división del trabajo por género en el día a día y en las acciones bélicas. Los campamentos sandinistas -que están segregados por sexo- no son totalmente ajenos a la cultura patriarcal; la distribución de tareas y honores invisibiliza el aporte de las mujeres, especialmente en el campo militar. La "exclusión de la cuenta" (Rancière) que afecta a las mujeres se revela en la canción "Eran 30 con él", la cual ignora su participación en la creación del EDSNN y las relega a un papel de figurantes. ${ }^{11}$

- Existe una amplia diversidad de mujeres y tipos sociales femeninos involucrados con la rebelión de Sandino, así como distintas formas de agencia femenina, tanto en los campamentos como fuera de estos. Sandino tiene simpatizantes entre las mujeres campesinas y populares (a quienes fascina con su "bonito modo"), pero también entre algunas mujeres acomodadas y económicamente más autónomas, como finqueras e intelectuales. El autor hace un esfuerzo por identificar con nombres y apellidos a las protagonistas más importantes.

- En conclusión, aunque Sandino mostraba mayor sensibilidad hacia las demandas de las mujeres, a la vez que era -al menos relativamente-consciente de su importancia para la lucha contra los bandoleros y los mariners; "nunca pretendió llevar a cabo una revolución social para acabar la discriminación contra la mujer... La identidad de género y sexualidad se mantuvieron" (276).

- No solo Sandino no fue un feminista, tampoco lo fueron las mujeres que participaron en su rebelión. Hasta donde el libro deja vislumbrar, ellas no alcanzaron un nivel de expresión y organización que les permitiera formalizar una agenda feminista dentro del primer sandinismo, aunque llegaron a reclamar "por la vía de los hechos: haciendo la guerra, la resistencia, en fin, adoptando 
comportamientos 'indecentes' que a todas luces marcó un antecedente de autodeterminación inusitado en una cultura y sociedad que las anulaba completamente" (279). ${ }^{12}$

En resumen, el libro estudia el lugar de las mujeres en la rebelión de Sandino mediante una exhaustiva revisión e interpretación de las fuentes disponibles. Como resultado, ofrece una valiosa aproximación a la participación de mujeres de distintos rasgos sociales en la lucha sandinista contra los conservadores y los ocupantes norteamericanos. Al mismo tiempo, muestra cómo los hombres, comenzando por el propio Sandino y sus colaboradores cercanos, así como sus oponentes, concebían y percibían el papel de las mujeres. La mayor sensibilidad de Sandino hacia los asuntos específicos de las mujeres le daba una suerte de "superioridad moral" sobre sus adversarios; por su parte, la participación de muchas mujeres, en distintos roles, fue fundamental para su lucha. Aunque Bendaña da algunas pistas, se requiere un estudio adicional para conocer la importancia logística y combativa que tuvieron las mujeres entre sus adversarios.

Para concluir, es pertinente apuntar una tarea pendiente, la cual corresponde menos al autor que a quienes deseen proseguir esta pionera indagación. Como señalamos, en parte por las características de las fuentes, pero también por su propia mirada, Bendaña reconstruye menos las voces de las propias mujeres que las de los hombres de uno y otro bando sobre ellas. Esa dificultad metodológica, que plantea también problemas políticos, deja abiertas las siguientes interrogantes: ¿Cómo neutralizar el sesgo masculino en el registro, en la interpretación y en el comentario?, ¿cómo interrogar a contrapelo -con sensibilidad feminista- a esas fuentes?, ¿cómo -en ausencia de testimonios directos- hacer hablar a las protagonistas ${ }^{13}$ Con esta reseña me he propuesto presentar mi propia lectura del valioso libro de Bendaña, pero también invitar a los lectores -y especialmente a las lectoras- a problematizar la mirada, la voz y la escritura masculina, con el propósito de dejar hablar a las "subalternas" o, mejor, de entablar un diálogo con ellas.

\section{Notas}

1 En cuanto a los conflictos previos a la rebelión sandinista, el libro menciona a las "Leonesas", protagonistas en el levantamiento y sitio de 1912 contra las tropas hondureñas y norteamericanas que ocuparon Nicaragua. Los testimonios de los invasores muestran el papel activo de esas mujeres, a las cuales califican -siguiendo una arraigada tradición de demonización de los subalternos- de "chusma enloquecida" y "demonizada". No obstante, las mujeres estaban en ambos bandos, como evidencia la coronela Rosa Farina, conservadora que -según una fotografía tomada, al parecer en Chinandega en 1927 (Bendaña 20), con "curiosidad antropológica y patriarcal" - comandaba un destacamento de mujeres. Según el autor, "Esta y otras fotografías rompen el mito del papel secundario de ellas en las guerras y la historia formal" (21). 
La manera en que los mariners trataron a las mujeres de clases acomodadas generó también una "reacción machista-nacionalista de abierto reclamo masculino a las mujeres vinculadas a marinos (sin que esto significara mayor simpatía por Sandino), al punto de provocar una marcha en Granada con la consigna "muerte a la mujer casada con un yanqui" (Bendaña 229). Gómez muestra cómo, en ese contexto, los escritores "reaccionarios" buscan construir una imagen virtuosa de la mujer, según el código colonial-hispano-católico, la cual será asumida como canónica también por Somoza García.

No se menciona Sandino. Una biografía política, de Wünderich. Ese voluminoso libro contiene un pequeño subcapítulo ("Sandino y las mujeres"), dedicado a dos de las tres mujeres con las que Sandino mantuvo relaciones sentimentales durante su lucha: Teresa Villatoro y Blanca Aráuz.

Ante una investigación militar ordenada por el embajador norteamericano, por los escándalos por violación, el jefe de los marinos habría respondido: “en relación con la violación de mujeres o intentos, lo consideramos absolutamente imposible porque las mujeres de allá son tan inmundas y repulsivas que no incitarían ni al soldado más desaliñado" (Bendaña 153). Los testimonios de algunos mariners arrepentidos, como William Gandall, confirmarían la crueldad de los ocupantes.

En el extremo opuesto a Somoza, otros biógrafos (como Gregorio Selser, Carlos Fonseca Amador y Miguel Littin) buscaron beatificar a Sandino, ocultando o minimizando su relación extramarital con Teresa Villatoro, una de las mujeres que combatió con personalidad propia contra la ocupación norteamericana. Empero, el propio Sandino disminuye el papel de Villatoro, cuando señala -además de su "carácter de la chingada"- que la necesitaba para que se ocupe de los "pequeños detalles". A diferencia de Bendaña, considero que la película de Littin (Sandino, 1991) le da a Villatoro un papel protagónico.

Sandino postulaba una "heterosexualidad sacrosanta" en su tropa: "De homosexualidad no se ha registrado ni un solo caso durante toda la guerra. Esas degeneraciones urbanas [¿modernas, americanas?] aquí son tabúes" (Bendaña 64) También disminuía moralmente a sus enemigos, al calificarlos como "afeminados" y "eunucos".

"[C]onforme a los cánones literarios patriarcales de su tiempo", Sandino "emplea la figura femenina como vehículo para llamar a la defensa de la patria, que de paso también es femenina. El EDSNN se proclama protector de la 'madre' patria y Sandino describe a Nicaragua como 'nuestra joven patria, es la morena tropical" (Manifiesto de San Jacinto) (Bendaña 50). En una ocasión, cuando le llevaron "de regalo" una adolescente, el general señalaría: "Esta niña es Nicaragua. / Y ella no va a ser de usted, / ni de nadie. / Nadie podrá violarla o regalarla" (Bendaña 51). Cincuenta años después de la muerte del héroe, este tópico estaba plenamente vigente: en un cartel conmemorativo del cuarto aniversario del triunfo del FSLN, la revolución es representada como una niña, con la leyenda "Estoy enamorado de esta chavala de cuatro años" (Bujard y Wirper).

En el apartado "La red de cuido", Bendaña señala la "superioridad moral" de los sandinistas sobre sus contrincantes, caracterizados por su inmoralidad y maltrato. En esa red, la cual respondía a "una genuina preocupación por el bienestar de toda la familia, incluyendo los hijos de los colaboradores civiles", Sandino tendría un papel importante, ya que "dedica buena parte de su correspondencia a conocer circunstancias personales" (Bendaña 135). Eso no significa, empero, "que los hombres compartieran el trabajo 'maternal"” (Bendaña 136).

9 Decía Engels: "Es un hecho curioso que con cada gran movimiento revolucionario aparece en primer plano la cuestión del 'amor libre'”. En la rebelión sandinista también "florecieron los 
amores en el campamento", muchos de ellos como "amores libres". Sandino, dice Bendaña, mostraba un "resabio de su formación anarco-sindical en México", por su condescendencia con las "mujeres de 'amores libres", de las cuales habría recibido apoyo en tareas de inteligencia ("el servicio secreto del EDSNN"), que "incluyeron la cama", y lograron obtener importante información de los mariners (Bendaña143). La otra cara de los amores era la nostalgia, los celos, las inseguridades de la separación, claramente reconocible en la nutrida correspondencia entre los combatientes y sus seres queridos (Bendaña 164). Por lo demás, Sandino eran consciente de los "riesgos operativos" que derivaban de las desavenencias amorosas dentro de su ejército.

El autor se pregunta si en ese "otro tipo de ejército" que era el EDSNN existían también "otro tipo de hombre". Sandino no era feminista, pero estaba al tanto de los derechos de las mujeres y, aunque la ciudadanía plena de la mujer no estaba entre sus preocupaciones centrales, tenía necesidad (operativa) de atraerlas e integrarlas en su movimiento, que así se favorece de su sensibilidad para "identificar y comprender las sentidas demandas de aquel segmento de la población" (Bendaña 82). Así, "solamente puede ofrecer una tregua en la guerra imperante contra las mujeres en el campo, o más precisamente, su protección en relación a la violencia en que el cuerpo y dignidad de la mujer es parte del terreno de combate y atropello cotidiano" (Bendaña 53). El encuentro "de los valores personales de Sandino con el imperativo operacional de hacer la guerra, sumado a la demanda de las mujeres de librarse de las bandas armadas mayoritariamente conservadoras", conduciría a Sandino a establecer un código de valores y buen comportamiento entre sus tropas. Ese propósito significaba "casi una revolución cultural en términos segovianos e históricos" (Bendaña 54), "contra un patrón cultural machista arraigado" (Bendaña 59).

11 Compuesta por Enrique Mejía Godoy, esa canción menciona a las mujeres que participaron y combatieron en la lucha de Sandino, pero no las incluye entre "los 30" que fundaron el EDSNN. Los versos dedicados a las mujeres son: "fue su ejército de niños, mujeres y hombres descalzos /... /que linda se ve /... / la compañera / haciendo la guardia en el campamento guerrillero /... / que linda se escucha la Adelita / que canta Pedrón con su batallón rumbo a Waslala".

No hubo una Kollontai que organizara a las mujeres con objetivos propios, planteara sus demandas específicas y estableciera un programa feminista (en el caso soviético, la agenda incluía la socialización del trabajo doméstico, la incorporación de las mujeres al empleo asalariado, la extinción de la familia y el amor (o unión) libre (Goldman). No obstante, sí existieron mujeres "insumisas" que no "quisieron ser guerrilleras de la cocina" e hicieron lo posible por resistir y mantener su independencia de ambos bandos (Bendaña 101). Una habría sido "la viuda de Flores", quien, sin embargo, para beneplácito del patriarcado entre los sandinistas, habría recibido un "escarmiento" por su desobediencia, ya que los mariners le destrozaron la propiedad (Bendaña 102). Otra fue la "comadre de Altamirano", que se negó a colaborar con Sandino y terminó "chalequeada" por Pedrón. Según Bendaña: "La comadre quiso desafiar el poder y le fue mal" (Bendaña110). Otras rechazarían la división de labores y las jerarquías de rango, para proclamarse soldados.

13 El sesgo masculino no está solo en las fuentes, sino también en su interpretación (y posiblemente en esta misma reseña). Por ejemplo, Bendaña narra una anécdota sobre un lío de amores en los campamentos sandinistas, al cual considera una "divertida historia", pese a que se podría también considerar un caso de tortura psicológica contra las mujeres involucradas en el hecho (el relato se encuentra en la página 183). 


\section{Bibliografía}

Bujard, Otker y Wirper, Ulrich. La revolución es un libro y un hombre libre. Los afiches de Nicaragua Libre 1979-1990 y del Movimiento de Solidaridad Internacional. Managua: IHNCA, 2010.

Butler, Judith. Cuerpos aliados y lucha política. Hacia una teoría performativa de la asamblea. Barcelona: Paidós, 2017.

Goldman, Wendy. "Del pasado hay que hacer añicos": La liberación de las mujeres y la Revolución Rusa". La Revolución rusa cien años después. J. Andrade y F. Hernández (eds.). Madrid: Akal, 2017.

Gómez, Juan Pablo. Autoridad/cuerpo/nación. Las batallas culturales en Nicaragua (1930-1943). Managua: IHNCA, 2015.

Heinich, Nathalie. El paradigma del arte contemporáneo: Estructuras de una revolución artística. Madrid: Casimiro, 2017.

Moore, Barrington. La injusticia: bases sociales de la obediencia y la rebelión. México: UNAM, 1989.

Rancière, Jacques. El desacuerdo. Política y filosofía. Buenos Aires: Nueva Visión, 2007.

Scott, James. Los dominados y el arte de la resistencia. México: Era, 2000.

Thompson, E. P. La formación de la clase obrera en Inglaterra. Madrid: Capitán Swing, 2012.

Wünderich, Volker. Sandino. Una biografía politica. Managua: Editorial Nueva Nicaragua, 1995.

Sergio Villena Fiengo. Costarricense-boliviano. Doctor en Estudios de la Sociedad y la Cultura (Universidad de Costa Rica), MSc. en Ciencias Sociales (FLACSO, Sede México), Licenciado en Ciencias Económicas (Universidad Mayor de San Simón, Cochabamba-Bolivia). Actual director del Instituto de Investigaciones Sociales de la Universidad de Costa Rica.

Contacto: sergio.villena@ucr.ac.cr

ORCID: 0000-0002-2864-8816 
